\title{
ECONOMIC IMPACT OF ALTERNATIVE FMD EMERGENCY VACCINATION STRATEGIES IN THE MIDWESTERN UNITED STATES
}

\author{
TED C. SCHROEDER* \\ Hall, Kansas State University \\ DUSTIN L. PENDELL \\ Associate Professor, Agricultural and Resource Economics, Colorado State University \\ MICHAEL W. SANDERSON \\ Professor, Production Medicine, Kansas State University
}

University Distinguished Professor, Agricultural Economics, Kansas State University, Agricultural Economics, Waters

SARA MCREYNOLDS

Graduate research assistant, Pathobiology, Kansas State University

\begin{abstract}
An outbreak of foot-and-mouth disease (FMD) in the United States would likely result in major costs to producers, consumers, and government. How animal health officials manage such an outbreak has substantial impact on probable losses. Without an emergency FMD vaccination strategy, producer and consumer losses of an FMD outbreak in the midwestern United States would likely approach $\$ 188$ billion, and government costs would likely exceed $\$ 11$ billion. In contrast, a high-capacity emergency vaccination program together with a large vaccination zone would reduce median consumer and producer losses to approximately $\$ 56$ billion and government costs to a little more than $\$ 1$ billion.
\end{abstract}

Key Words. economic impact of FMD outbreak, emergency vaccination, FMD outbreak

JEL Classifications. Q11, Q18, Q13

\section{Introduction}

A major outbreak of a highly contagious foreign animal disease in the United States would have severe economic consequences. For example, median losses associated with a potential foot-and-mouth disease (FMD) outbreak originating from the proposed National Bio and Agro-Defense Facility in Kansas could exceed \$100 billion (U.S. Department of Homeland Security, 2012). Economic impacts of an FMD outbreak include the cost of control efforts, the value of

This study was partially funded by the National Center for Foreign Animal and Zoonotic Disease Defense (FAZD Center).

*Email: tcs@ksu.edu 
infected or exposed animals that are euthanized and disposed of and associated immediate and longer-term supply shocks, probable reductions in domestic meat demand, and prolonged export market closures. The strategies employed by animal health officials in the event of an FMD outbreak can dramatically impact the expected disease spread, the number of animals that need to be destroyed, and the duration of the outbreak. Essential in assessing alternative disease management strategies that animal health officials might employ is estimating the expected economic impact of alternative strategies.

A long-standing debate in FMD control plans is whether to deploy emergency vaccination plans in conjunction with other disease mitigation strategies during an FMD outbreak (Armbruster, 2002). Emergency FMD vaccination is controversial for a variety of reasons including (1) concerns about vaccinated animals not being distinguishable from infected animals, (2) probable delays in being able to attain World Organisation for Animal Health (OIE) FMD-free without vaccination status after an epidemic limiting export market access, (3) costs of vaccinating, (4) uncertainty regarding the overall value of vaccinating relative to other FMD control measures, and (5) uncertainty regarding vaccine supplies and availability when needed. Emergency vaccination plans may be able to reduce disease spread duration by enabling animal health officials to curtail outward spread of the disease (Barnett et al., 2002). In addition, binding constraints on animal health officials' ability to stamp out animals as rapidly as needed to contain a major epidemic in a concentrated animal production region having large herds could make emergency vaccination a viable alternative to help reduce the rate of disease spread.

However, little is known about the value of alternative vaccination strategies in the United States. That is, uncertain are the economic impacts of vaccinate to die versus vaccinate to live, vaccination capacity constraints, or impacts of employing different sizes of emergency vaccination zones around infected herds. ${ }^{1}$ This study was designed to address this gap in information. Results provide U.S. animal health officials and policy makers with economic trade-offs of alternative FMD mitigation strategies that have not been addressed in previous work but need to be evaluated. Alternative FMD outbreak mitigation strategies need to be assessed in part based on prospective economic impacts provided in this study.

This study estimates the economic impacts of alternative FMD disease management strategies in the United States focused on emergency vaccination protocols. The objective is to estimate changes in consumer surplus and returns to capital and management for producers associated with alternative FMD disease management scenarios that incorporate emergency vaccination as a control measure. In particular, we assess economic impacts on producers, consumers, and government of alternative FMD vaccination deployments, vaccination capacities,

1 The vaccination zone is the diameter of the zone around infected herds where a vaccination program for all susceptible animals is implemented according to the established vaccination priority. 
vaccinating to live versus to die, and selected vaccination zone sizes around infected herds during a disease outbreak.

The information gleaned from this study is necessary for understanding the relative economic impacts of alternative FMD control measures animal health officials might employ in the event of an outbreak. Alternative control strategies reveal substantial variation in economic impacts that must be understood in designing disease containment and eradication plans.

\section{Background}

FMD is a highly contagious viral disease affecting cloven-hoofed mammals including bovine, swine, ovine, and cervids. The disease is easily spread directly through animal contact and indirectly through contaminated farm facilities, feed sources, vehicle movement, contaminated clothing, air, and raw meat. The last FMD outbreak in the United States occurred in 1929. The U.S. livestock herd is completely susceptible to FMD increasing the likelihood of a widespread epidemic that would cause substantial animal health and economic risk if it were introduced.

FMD is a global animal health threat that has experienced escalated concern in recent years because of frequent outbreaks around the world including in a number of previously long-standing FMD-free countries (Grubman and Baxt, 2004). For example, in 2008 and 2009, 13 and 38 countries, respectively, notified the OIE of FMD outbreaks (OIE, 2012a). OIE maintains a list of countries and zones free of FMD where vaccination is not practiced (the current U.S. status) or FMD free where vaccination is practiced. Stringent meat export restrictions are imposed on meat sourced from countries that are not FMD free as detailed in the OIE "Terrestrial Animal Health Code" (2012b). In particular, only cooked or processed meat from FMD-infected countries is typically allowed for import.

Countries that are FMD free with vaccination realize export market constraints relative to countries that are FMD free without vaccination. Meat products from countries designated by OIE as FMD free without vaccination realize price premiums of $10 \%$ to $50 \%$ in world markets (Rich, Winter-Nelson, and Brozović, 2005). As such, in addition to animal losses incurred to control the disease, a major concern for a meat-exporting country like the United States is the probable impact of an FMD outbreak on export market access and how that access might be affected by emergency vaccination. Furthermore, domestic meat demand is also likely to be adversely impacted by an FMD outbreak even though no human health risk is present from either the infected animal or from consuming meat produced from infected animals.

Several studies have estimated economic impacts of FMD outbreaks in the United States. Hagerman et al. (2012) compared economic impacts of two different hypothetical FMD outbreaks in localized short-run disease spread models, one in the California central valley and one in the Texas 
panhandle. Economic losses for FMD vaccination programs exceeded those for no vaccination in California but were about the same in Texas. FMD outbreaks had mean welfare losses ranging from $\$ 2.7$ billion to $\$ 21.9$ billion.

Elbakidze et al. (2009) estimated economic impacts associated with time-todisease detection, slaughter capacity of infected herds, and timing availability of FMD vaccine under alternative site introductions of the disease. The disease spread model was regional and limited to the Texas panhandle. The outbreak was estimated to cost up to $\$ 1$ billion to the local cattle industry. Similar to Hagerman et al., Elbakidze et al. concluded that vaccination strategies were generally not cost effective as a disease control. Pendell et al. (2007) studied hypothetical outbreaks of FMD in Kansas originating in different beef cattle operation types and sizes. Their model considered a regional outbreak limited to a 14-county region located in a concentrated cattle feeding area in southwest Kansas. They found that for the local economy, the outbreak could result in as much as a $\$ 1$ billion loss.

The studies by Hagerman et al. (2012), Elbakidze et al. (2009), and Pendell et al. (2007) are particularly useful for helping establish probable short-run localized impacts of hypothetical FMD outbreaks. Our study has a much larger geographic area in the epidemiology modeling including a region encompassing all or parts of eight states located in the midwestern United States. As a result, we allow for much larger geographic disease spread outbreaks that may last longer than the outbreaks simulated in more localized studies. Another important component of our model, though not unique to our study, is incorporating expected trade bans associated with the disease outbreak in the economic modeling. A major driver of probable economic impact of an FMD outbreak is the importance of trade and associated trade bans. In countries where export markets are important, the economic impact of trade bans associated with FMD can rapidly exceed the direct economic impact of the disease itself in the infected country (Mangen, Nielen, and Burrell, 2002; Niemi and Lehtonen, 2011; Paarlberg and Lee, 1998; Paarlberg, Lee, and Seitzinger, 2003; Schoenbaum and Disney, 2003). In contrast, a meat importer would realize a markedly different impact of FMD than an important exporter (Nogueira et al., 2011).

One of the major issues in the midst of an FMD outbreak is whether to engage an emergency vaccination plan as part of the disease control strategy (Barnett et al., 2002). Historically, one concern with employing a vaccination program was that vaccinated animals could not be distinguished from infected animals, though development of new vaccines and diagnostic tests are underway to allow such distinction. As such, some high-value meat export markets like Japan and Korea do not allow full market access for countries that vaccinate (Ekboir et al., 2002). Furthermore, under OIE guidelines, a country that vaccinates and does not slaughter the vaccinated animals (vaccinate to live) must wait six months following the last case or last vaccination when a stamping-out policy and serological surveillance are carried out before regaining FMD-free 
status compared with waiting three months if animals are slaughtered following vaccination.

An FMD outbreak in 2001 in the United Kingdom resulted in some 6.5 million animals culled for disease control, and the epidemic was estimated to cost between $\$ 12.3$ billion and $\$ 13.8$ billion (Scudamore and Harris, 2002). In the 2001 FMD outbreak in the United Kingdom, an emergency vaccination program was not deployed. In retrospect, the Royal Society recommended that a vaccination-to-live policy would have better served the industry by allowing meat from vaccinated animals to enter the food chain, and this is the likely policy going forward in the United Kingdom (Grubman and Baxt, 2004).

Recently, U.S. health officials have begun to more widely consider emergency FMD vaccination as a plausible response in an outbreak. Without a vaccination strategy, physical constraints of stamping out animals (preferred FMD control strategy in the United States) rapidly enough to contain the disease become important limiting constraints. Results of a survey of seven prominent national animal health officials in the United States in 2011 identified several factors most important to consider in whether or not to vaccinate animals. The top three were (1) capability to manage the outbreak with stamping out, (2) rate of outbreak spread, and (3) size of outbreak (Parent, Miller, and Hullinger, 2011). Our study illustrates the economic impacts that an effective emergency vaccination strategy deployed with an ongoing stamping-out program can have in the event of an FMD outbreak in the United States. We simulate FMD introduction in the heart of a major cattle-producing region in the midwestern United States. The region is characterized by both smaller open-grazing operations and also by large confined animal production operations that have considerable animal movement and significant traffic in and out of these operations. These characteristics, together with susceptibility of the animal population to FMD, suggest that introduction of the disease in the region could have a high probability of becoming a major epidemic.

Several studies have assessed the impact of alternative emergency vaccination strategies on FMD outbreaks. In general, mixed conclusions exist regarding the overall value of emergency vaccination strategies. Some studies question the value of vaccination because of the costs of vaccination, loss in animal value for vaccinated herds, irreversibility of the decision, and/or extended export market access problems with vaccination (Elbakidze et al., 2009; Mahul and Gohin, 1999; Zhao, Wahl, and Marsh, 2006). Other studies suggest that depending on the circumstances of the disease spread, duration, and the costs of compensation for depopulated animals, an emergency vaccination plan might be justified because it may significantly reduce the duration of the epidemic (Burrell and Mangen, 2001; Rich and Winter-Nelson, 2007). If stamping out cannot rapidly contain the disease and it appears to have potential to become a widespread epidemic, U.S. animal health officials believe vaccination is a disease management tool to consider using (Parent, Miller, and Hullinger, 2011). 
Important for assessing the potential value of an emergency vaccination plan is to understand how the design and constraints of the vaccination strategy employed affect the economic consequences of an outbreak. In particular, several aspects of an emergency vaccination plan may have substantial impact on the ability to control the disease and the ultimate economic impact, including (1) whether a vaccinate-to-live or vaccinate-to-die policy is employed, (2) whether targeted vaccination of large cattle feedlots is used, (3) the vaccination capacity that can be achieved, (4) the vaccination trigger used to determine when to begin a vaccination program, and (5) the size of the vaccination zone around infected herds that is used. Our study assesses the aggregate economic impacts on producers and consumers in the United States of these emergency vaccination program characteristics. The intent of this analysis is to help better inform policy makers and animal health officials regarding the probable economic impact of alternative emergency FMD vaccination protocols and constraints. Substantive unique contributions of our study include the broad geographic region for disease spread, which is more realistic than localized disease spread models, and the variants in types of vaccination strategies compared, which necessitate investigation to assess probable impacts. We are aware of no existing study that combines these two essential dimensions to assess the economic impact of alternative FDM mitigation scenarios.

\section{Economic Model}

The economic model used in this study is a multimarket and multicommodity quarterly partial equilibrium model of the U.S. agricultural sector. The model incorporates both vertical and horizontal linkages starting with livestock production through to the final consumer, including international trade. In addition to livestock and meat markets, grain sectors are incorporated in the model as feed is a major input into livestock production.

A summary description of the conceptual model is presented here (complete documentation is provided in Paarlberg et al., 2008). ${ }^{2}$ The economic model is a quarterly demand and supply model. Final consumer demand is modeled for 10 separate goods (beef, pork, poultry, lamb, diary, eggs, wheat, rice, coarse grains, and soy oil). Final demand (per capita consumption) depends on retail price and per capita income. Demand shocks can be introduced to simulate possible changes in consumer demand associated with animal disease events.

Supply of final goods is modeled for meat, milk, eggs, rice, coarse grains, wheat, and soybean oil for each industry and sector. Linkages between vertical segments of the livestock production sectors (separate sectors include beef cattle,

2 The conceptual model is available at: http://www.ers.usda.gov/media/210513/err57appa_1_.pdf. The numerical data are reported in: http://www.ers.usda.gov/media/210517/err57appb_1_.pdf. 
hogs, dairy, poultry meat, layers, and sheep and lambs) occur through derived demands for animals for slaughter (net of trade) to live animal inventory and derived demands for feedstuffs. Each production sector is modeled to capture dynamic inventories with appropriate biological quarterly lags to capture production lags as well as linked animal flows through the various production phases. Crop supplies are modeled for wheat, coarse grains, soybeans, rice, and forage and pasture.

Overall, closure of the model requires market-clearing domestic and international trade prices and quantities. Excess demand and supply equations are used to model imports and exports. Exports and imports are modeled allowing for trade interventions. In particular, most germane for this study, exports can be shocked (similarly to the domestic demand shocks discussed previously) as market access restrictions or bans may occur in the event of an FMD outbreak. Finally, vertical market prices at farm, wholesale, and retail are modeled using margin markup equations based on U.S. Department of Agriculture (USDA) margin calculations.

The structural model of demand and supply relationships is transformed through total logarithmic differentiation to facilitate use of elasticities to quantify estimates. All the economic model parameters, substitution and trade elasticities, revenue and factor shares, and livestock-feed balance information remain constant throughout the model and are defined by Paarlberg et al. (2008). Updated parameters used in our model relative to the specifications of Paarlberg et al. (2008) include retail-level demand elasticities for beef, pork, and poultry (Tonsor, Mintert, and Schroeder, 2010); lamb (Shiflett et al., 2007); and milk (Zheng and Kaiser, 2008). The model assumes naïve price expectations for all scenarios (Paarlberg et al., 2009).

The modeling framework used here links output regarding the number of animals culled, duration of outbreak, and number of animals vaccinated from an epidemiological disease spread model (the North American Animal Disease-Spread Model, or NAADSM) to the partial equilibrium economic model to estimate the economic impacts on the agricultural sector. Essentially, the NAADSM output enters the economic model as exogenous shocks to supply equations. The economic model assesses the impacts of an FMD outbreak on livestock for agricultural inputs (coarse grains, wheat, rice, soybeans, soybean meal, soybean oil, and forage and pasture), production (cattle, hogs, poultry, lamb and sheep, dairy, and eggs), processing (cattle, hogs, lamb and sheep, and poultry and birds), and consumption (beef, pork, poultry, lamb and sheep, dairy, eggs, rice, coarse grains, wheat, and soybean oil). The economic impacts are simulated beginning the first quarter of 2009 (corresponding to the initial simulated FMD outbreak) through the fourth quarter of 2018 (40 quarters). In addition to assessing the impacts of domestic production through changes in supply, international trade is evaluated by allowing for export market bans of livestock and meat products. The model also allows for measuring the economic 
impacts of an FMD outbreak due to possible changes in domestic consumer perceptions of food quality and health risks.

\subsection{Shocks}

In the event of an FMD outbreak, it is assumed per NAADSM that infected and exposed animals will be depopulated (supply shocks), international trade partners will immediately suspend or restrict trade (international trade demand shocks) (OIE, 2012b), and domestic consumers will reduce consumption of meat (excluding poultry) and dairy products due to perceived health risks (domestic demand shocks).

\subsection{Supply}

The numbers of animals depopulated are taken from NAADSM simulations of an FMD outbreak initiated in a northeast Colorado feedlot. The animals stamped out were converted to percentage changes in supply and incorporated into the economic model. Excluding a no vaccination (NOVAC) scenario, emergency vaccination was assumed in all the FMD outbreaks (Table 1). Two alternative emergency vaccination scenarios were assumed in most of the NAADSM scenarios: vaccinate to die (D) or vaccinate to live (L). We assumed all feedlot animals vaccinated would go to commercial slaughter at harvest whether they were vaccinated to live or die. For all other animals, we assumed those vaccinated to die were depopulated the quarter they were vaccinated and those vaccinated to live were retained in respective herds until normal culling/harvest.

\subsection{Demand}

Although there are no known human health risks from FMD, consistent with previous studies (Paarlberg, Lee, and Seitzinger, 2002; U.S. Department of Homeland Security, 2012), we expect that domestic consumer demand would decline in the event of an FMD outbreak because of perceived health and food safety risks. We assumed the same domestic consumer response as used in the Department of Homeland Security's (2012) recent study, which was developed using previous literature from FMD and other disease outbreaks and food safety events. For outbreaks that last less than one quarter, we assumed a $5 \%$ reduction in domestic consumer demand for beef, pork, and lamb and a $2.5 \%$ reduction in milk and dairy product demand during that quarter of the outbreak. In the second quarter, consumer demand for beef, pork, and lamb was assumed to begin to recover but was still lower by $2.5 \%$ relative to the base year, and milk and dairy product demand was assumed to fully recover. Consumer demand would be fully recovered by the beginning of the third quarter for beef, pork, and lamb.

In outbreaks lasting beyond one quarter, consistent with the Department of Homeland Security (2012) study, we assumed that $10 \%(5 \%)$ of consumers would refrain from consuming beef, pork, and lamb (milk and dairy products) 
Table 1. Summary of Foot-and-Mouth Disease Outbreak Scenarios

\begin{tabular}{lrclc}
\hline \hline & $\begin{array}{l}\text { Vaccine } \\
\text { Strategy }^{b}\end{array}$ & $\begin{array}{l}\text { Vaccination } \\
\text { Capacity (Herds, } \\
\text { Day 22, Day 40) }\end{array}$ & $\begin{array}{l}\text { Vaccination } \\
\text { Trigger } \\
\text { (Herds) }^{\mathrm{d}}\end{array}$ & $\begin{array}{l}\text { Size of } \\
\text { Vaccination } \\
\text { Zone }(\mathrm{km})^{\mathrm{e}}\end{array}$ \\
\hline NOVAC & None & - & - & - \\
D5/10/10 & V2D & 5,10 & 10 & 10 \\
L5/10/10 & V2L & 5,10 & 10 & 10 \\
D1/10/10 & Vfd2D & 1,3 & 10 & 10 \\
D5/10/50 & V2D & 5,10 & 10 & 50 \\
L5/10/50 & V2L & 5,10 & 10 & 50 \\
D1/10/50 & Vf2D & 1,3 & 10 & 50 \\
D5/100/10 & V2D & 5,10 & 100 & 10 \\
L5/100/10 & V2L & 5,10 & 100 & 10 \\
D5/100/50 & V2D & 5,10 & 100 & 50 \\
L5/100/50 & V2L & 5,10 & 100 & 50 \\
D50/10/10 & V2D & 50,80 & 10 & 10 \\
L50/10/10 & V2L & 50,80 & 10 & 10 \\
D50/10/50 & V2D & 50,80 & 10 & 50 \\
L50/10/50 & V2L & 50,80 & 10 & 50 \\
\hline \hline
\end{tabular}

a Scenario name: NOVAC, no vaccination. Each scenario is uniquely labelled here with a naming convention that succinctly indicates whether animals are vaccinated to live $(\mathrm{L})$ or die $(\mathrm{D})$ and vaccination capacity (1,5, or 50 herds per day)/vaccination trigger (10 or 100 herds) /size of vaccination zone (10 or $50 \mathrm{~km})$.

${ }^{b}$ Vaccine strategy: vaccinate to die is denoted as V2D—all animals vaccinated are subsequently destroyed. Vaccinate to live is denoted as V2L-vaccinated animals are not destroyed (only infected herds/animals are destroyed). Vfd2D is when cattle in large feedlots ( $\geq 3,000$ head) are vaccinated and subsequently fed out for slaughter.

${ }^{c}$ Vaccination capacity: number of herds vaccinated per day at 22 days and 40 days after first disease detection. For example, 5,10 refers to 5 herds per day at 22 days and 10 herds per day at 40 days.

${ }^{\mathrm{d}}$ Vaccination trigger: number of herds infected before the vaccination strategy is implemented.

${ }^{\text {e }}$ Size of vaccination zone: diameter of vaccination zone in kilometers around infected herds.

during the outbreak. After the outbreak was over, consumer demand would remain reduced by $5 \%(2.5 \%)$ for one quarter and $2.5 \%$ (fully recovered) for another quarter for beef, pork, and lamb (milk and dairy products). In the following quarter, consumer demand for red meat was assumed to be fully recovered.

Similar to the domestic consumer demand shocks, we assumed the response of U.S. international trading partners would follow the U.S. Department of Homeland Security (2012) study. First, 95\% of all U.S. exports of red meat (beef, pork, and lamb meat) and live animals (cattle, swine, and sheep) would be halted during the outbreak and for one full quarter after the last FMD case appeared when no emergency vaccination and emergency vaccination with depopulation of the vaccinated animals (i.e., vaccinate to die) was used. When emergency vaccination was practiced and depopulation of the vaccinated animals did not occur (i.e., vaccinate to live), it was assumed that exports would be interrupted 
Table 2. Estimated Government Costs of Managing a Foot-and-Mouth Disease Outbreak

\begin{tabular}{lrrrrr}
\hline \hline & \multicolumn{5}{c}{ Sector } \\
\cline { 2 - 6 } Activity & Cow-Calf & $\begin{array}{r}\text { Feedlot } \\
\text { (\$/Head) }\end{array}$ & $\begin{array}{r}\text { Dairy } \\
\text { Swine }\end{array}$ & Sheep \\
\hline Euthanasia & $\$ 80$ & $\$ 50$ & $\$ 64$ & $\$ 24$ & $\$ 70$ \\
Indemnity & $\$ 1,021$ & $\$ 745$ & $\$ 1,862$ & $\$ 59$ & $\$ 84$ \\
Vaccination costs & $\$ 28$ & $\$ 22$ & $\$ 22$ & $\$ 12$ & $\$ 31$ \\
Disposal & $\$ 53$ & $\$ 31$ & $\$ 41$ & $\$ 10$ & $\$ 43$ \\
Cleaning and disinfecting & $\$ 33$ & $\$ 21$ & $\$ 54$ & $\$ 7$ & $\$ 27$ \\
Total & $\$ 1,187$ & $\$ 847$ & $\$ 2,021$ & $\$ 100$ & $\$ 224$ \\
\hline \hline
\end{tabular}

Source: Miller and Gallagher (2010).

for two quarters beyond the end of the outbreak. This is consistent with the OIE FMD guidelines (OIE, 2012b). In all cases modeled, vaccination was ceased at the end of the active outbreak. Second, after the additional quarter ends with no FMD reported, U.S. exports of the embargoed livestock and meat products were assumed to gradually recover until full recovery occurred approximately two years after the outbreak was over (U.S. Department of Homeland Security, 2012). This two-quarter extension allows time for additional follow-up surveillance required for reestablishment of FMD-free without vaccination status consistent with the OIE guidelines following a vaccinate-to-live policy (OIE, 2012b).

The partial equilibrium model solves for the percentage changes in the endogenous variables (prices and quantities) for each quarter and each agricultural sector. The percentage changes are compared with a baseline defined by the observed/forecasted data without any FMD outbreak, for the first quarter of 2009 through the fourth quarter of 2018 (40 quarters).

\subsection{Government Costs}

In addition to losses that would accrue to producers and consumers under an FMD outbreak, government health organizations would incur direct costs to manage and mitigate the outbreak. Government costs include euthanasia, disposal and indemnity costs for animals that are depopulated, vaccination costs for animals that undergo emergency FMD vaccination, and premises cleaning and disinfecting following depopulation. Indemnity costs use average annual values for 2008, the year before the assumed starting point of 2009 .

Government costs per head by species are summarized in Table 2 . These costs are multiplied by the numbers of animals subjected to each specific activity (i.e., 
depopulated, vaccinated, disposed of, etc.) under each scenario to estimate total government costs associated with that scenario. ${ }^{3}$

\subsection{Consumer and Producer Measures}

Economic impacts of various FMD control strategies are measured using economic surplus estimates. Consumer surplus is the standard surplus measure (i.e., difference between what consumers are willing to pay for a product and what they actually pay for the product), and producer returns are the revenue minus variable costs. The consumer surplus is for U.S. consumers of beef, pork, poultry meat, lamb and sheep meat, dairy products, eggs, rice, coarse grains, wheat, and soybean oil. The producer returns include the following: animal agriculture (cattle, hogs, birds, sheep, eggs, and dairy cows); animal processing (beef and cattle, pork and hogs, lamb and sheep meat, and poultry meat and birds); and crops (wheat, coarse grains, rice, soybeans, soybean meal, soybean oil, forage, and pasture).

\section{Animal Disease Spread Model and Management Scenarios}

The disease spread modeling process is designed to simulate an FMD outbreak in the heart of the commercial cattle-producing region of the United States. The disease spread modeling was conducted using the NAADSM, which is a stochastic, spatially explicit, state-transition simulation model for the spread of highly contagious diseases of animals (Harvey et al., 2007). ${ }^{4}$ NAADSM requires extensive data for parameterization including contact rates and distances between livestock types and supporting industries. For example, the rate of direct contact via shipment of animals between cow-calf operations and dairy operations and the indirect rate of contact between cow-calf and dairy operations through a feed truck that visits both operations are necessary parameters to be estimated when simulating outbreaks using NAADSM. Briefly, a cluster of animals in a herd is the base unit for simulation. Production type (e.g., cow-calf or feedlot) of herds is defined by the user. Herds exist in one of seven health status states: susceptible (animals susceptible to disease), latent (infection present in the herd, but animals not shedding or infectious), subclinically infectious (animals shedding and infectious but with no clinical signs of disease), clinically infectious (animals shedding and infectious and showing clinical signs), naturally immune (animals in the herd progressed through disease to an immune status), vaccine immune (animals in the herd are vaccination immune to infection), or destroyed (animals in the herd depopulated). Disease state durations (except for susceptible

3 Euthanasia, indemnity, vaccination, animal disposal, and cleaning/disinfecting costs were obtained from Miller and Gallagher (2010). Government surveillance costs are another cost that government health officials face in monitoring an FMD outbreak. Estimates of surveillance costs are provided in Hagerman et al. (2012). Surveillance costs would be small relative to the costs included in our study.

4 NAADSM documentation is available at: http://www.naadsm.org/about. 
and destroyed) are defined by probability density functions that are specific to each disease state and production type. Herds remain in the susceptible state until infection is introduced and then progress through the disease states according to defined probability density functions. At any point, herds may enter the vaccine immune or destroyed state based on vaccination or depopulation as defined in the model settings (e.g., what herd states are eligible or depopulation) and the stochastic actions of the model. The time step for the model is one day.

Disease spread can be the result of direct contact (animal movements), indirect contact (contact through equipment, feed, or people), or local airborne spread. Direct contact rates must be specified for each production type combination. Contacts are generated between specific infectious herds (latent, subclinical, or clinical) and a susceptible herd based on a Poisson distribution with mean equal to the mean direct contact rate between the two specific production types (e.g., between cow-calf herds and small feedlots). A distance for the direct contact is chosen from the probability density function for shipment distance between the specific production types, and a receiving herd closest to that distance from the infectious herd is chosen to receive the contact. Indirect contacts are similarly simulated; however, only subclinical and clinical herds can be the source of infection by indirect means. Indirect contact rates are specifically defined for each production type combination, and contacts are generated based on a Poisson distribution with mean equal to the mean indirect contact rate between the two specific production types. Airborne spread can occur from subclinical and clinical herds to susceptible herds based on the probability of spread at $1 \mathrm{~km}$, the distance between the herds and the size of the source and recipient herds. Actual airborne transmission between the infectious and susceptible herd is generated based on a random number $r$ (in the interval 0,1) where infection is transmitted when $r$ is less than the calculated probability of transmission.

Herds are identified as infected based on user-defined relational functions of the probability of observing and reporting clinical signs in the herd over time from first infection. The model generates a random number that if greater than the probability of detection for that day, results in identification of the infected herd.

Infected herds are placed in quarantine following detection and scheduled for depopulation. Quarantined herds do not receive or generate direct contacts but do generate and receive indirect and airborne contacts. Depopulation and vaccination of herds is based on user-defined criteria, priorities, and capacity (number of herds per day). Direct and indirect contact rates between herds are based on survey data of livestock producers in Kansas and Colorado (McReynolds et al., 2014).

Based on data from the USDA (2009) National Agricultural Statistics Service, a simulated population of livestock operations was generated for use in NAADSM. The population included the states of Kansas, Nebraska, Colorado, South Dakota, and Wyoming, as well as northern Oklahoma, the panhandle of Texas, 
Table 3. Summary of Population of Animals and Herds used in North American Animal Disease-Spread Model by Production Type

\begin{tabular}{lrr}
\hline \hline Production Type & \multicolumn{1}{c}{ Animals } & \multicolumn{1}{c}{ Herds } \\
\hline Cow-calf & $9,698,630$ & 86,655 \\
Feedlot-large $(\geq 3,000$ head $)$ & $9,147,279$ & 979 \\
Feedlot-small $(<3,000$ head $)$ & $7,377,698$ & 25,096 \\
Dairy & $1,062,276$ & 3,232 \\
Swine-large $(\geq 1,000$ head $)$ & $9,227,569$ & 1,071 \\
Swine-small $(<1,000$ head $)$ & 663,465 & 6,463 \\
Beef-swine mix & 520,283 & 5,159 \\
Sheep & $1,716,028$ & 22,965 \\
Total & $39,413,228$ & 151,620 \\
\hline \hline
\end{tabular}

Note: In our economic modeling, we grouped large and small feedlots into a single category called feedlots; we grouped cow-calf and half of beef-swine mix into cow-calf; and we grouped large and small swine and half of beef-swine mix into swine.

Sources: U.S. Department of Agriculture (2009) and Melius, Robertson, and Hullinger (2006).

and northern New Mexico. Production types in the population included mixed beef-swine, cow-calf, large and small feedlot, dairy, large and small swine, and small ruminant (sheep and goats). ${ }^{5}$ The population included 151,620 herds defined by latitude and longitude, production type, and herd size (Table 3). Total population was $39,413,228$ animals in all production types. In all the FMD outbreak scenarios, a single one-time capacity 17,000-head feedlot located in northeast Colorado was selected as the initial latently infect herd in an otherwise susceptible population. Scenarios were simulated for various FMD vaccination protocols compared with the scenario of a stamping out depopulation of infected animals only. The FMD vaccination protocols varied by (1) vaccinated to live or die, (2) vaccination capacity, (3) vaccination trigger used to determine when to begin a vaccination program, and (4) the size of the vaccination zone around infected herds.

Fifteen separate scenarios were run to assess the impact of differing FMD vaccination control methods on economic impact (Table 1). To facilitate discussion, each scenario is uniquely labelled here with a naming convention that succinctly indicates whether animals are vaccinated to live (L) or die (D) and vaccination capacity $(1,5$, or 50 herds per day)/vaccination trigger (10 or 100 herds)/size of vaccination zone (10 or $50 \mathrm{~km}$ ) (see Table 1$)$. For example, scenario D5/100/50 is a vaccinate to die with a vaccination capacity of 5 herds per day at 22 days and 10 herds per day at 40 days/vaccination trigger of 100 herds/vaccination size of $50 \mathrm{~km}$.

5 In our analysis, we grouped large and small feedlots into a single category called feedlots; we grouped cow-calf and half of beef-swine mix into cow-calf; and we grouped large and small swine and half of beef-swine mix into swine. 
For all scenarios, (1) the number of days to first disease detection was generated by the NAADSM model; (2) the probability of indirect disease transmission following contact between an infected and susceptible herd was held fixed at $20 \%$ for all production types except swine, which was set at $30 \%$ to account for increased shedding; (3) animal movement was restricted to $30 \%$ of pre-outbreak levels; and (4) depopulation capacity was set at 8 herds per day by day 10 and 16 herds per day by day 30 after disease detection. Vaccination priority, from highest to lowest, for all scenarios was as follows: large feedlot ( $\geq 3,000$ head), small feedlot $(<3,000$ head), large swine $(\geq 1,000$ head), small swine ( $<1,000$ head), beef-swine, dairy, cow-calf, and small ruminant (sheep). The vaccination trigger, the number of herds that are infected before an emergency vaccination program is implemented, was set at either 10 or 100 herds.

Vaccination capacity, in herds per day, was varied with different scenarios (Table 1). Simulated vaccination protocols included low to high vaccine capacity based on results from a livestock producer survey (McReynolds et al., 2014). We model two low-capacity vaccination plans to represent USDA personnel administering or supervising all vaccinations in addition to instances in which the capacity would be larger than USDA personnel could supervise, requiring producers to administer vaccinations. The low-capacity vaccination protocols were as follows: (1) 1 herd per day by 22 days after disease detection and 3 herds per day by 40 days after disease detection, and (2) 5 herds per day by 22 days after disease detection and 10 herds per day by 40 days after disease detection. The high-capacity vaccination protocol, representing producers administering vaccinations to their herds, had capacity of 50 herds per day by 22 days after disease detection and 80 herds per day by 40 days after disease detection. Given the vaccination capacity constraints we have assumed in the disease spread model, the majority of the FMD outbreak scenarios examined here result in mostly cattle in large feedlots only being vaccinated. Animal health officials generally do not support producers administering FMD vaccine because it is a restricted and controlled vaccine. Our analysis assesses the impact of such a restriction. For each scenario, NAADSM was simulated 200 times to generate a distribution of disease spread outcomes. ${ }^{6}$ The results from the daily NAADSM model are summed to quarterly values and used as supply shocks in the quarterly economic model.

6 We monitored the mean, 5th and 95th percentiles of outbreak duration, number of destroyed herds, and number of animals vaccinated for convergence. All monitored outputs showed less than $4 \%$ change at 200 iterations for all scenarios. Most scenarios converged at approximately 100 iterations, and all scenarios converged before 200 iterations. These values are similar to (Ward et al., 2009). 


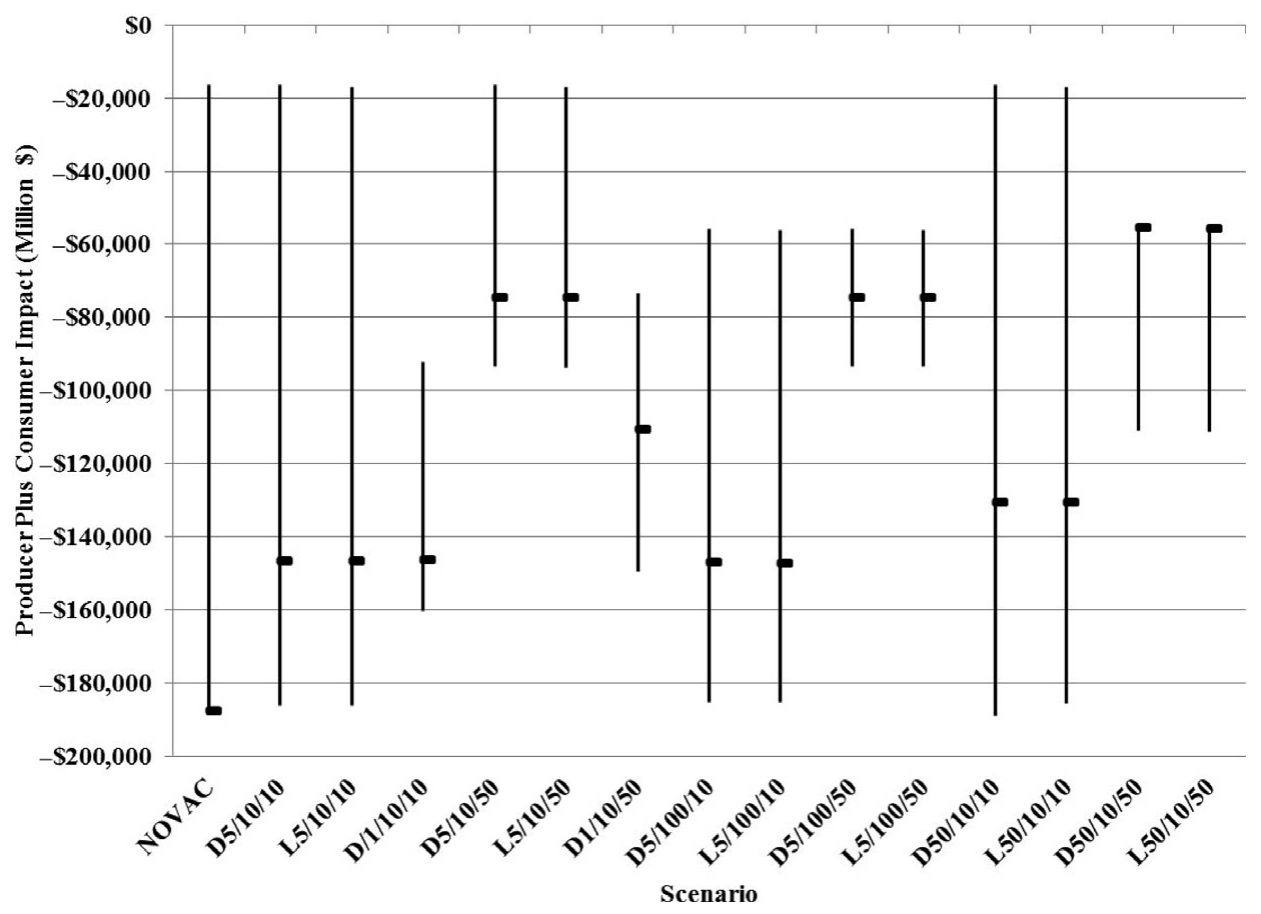

Figure 1. Estimated 10th, 50th, and 90th Percentile Disease Duration Confidence Intervals of Total Consumer Surplus Plus Producer Returns to Capital and Management Impacts of an FMD Outbreak under Alternative Disease Management Scenarios (as Defined in Table 1)

\section{Results}

We report 10th, 50th, and 90th percentiles of outbreaks based on disease duration. The distributions of outbreak economic outcomes are a result of variation in NAADSM epidemiology results as the economic model parameters are assumed fixed. Disease duration is used in place of the commonly used numbers of animals depopulated to report confidence bands on the economic impacts because domestic and export market demand changes are driven off of disease duration, not numbers of animals depopulated. Changes to producer returns to capital and management and consumer surplus are presented in Table 4 and Figure 1 cumulated over the 40-quarter period (first quarter 2009 to fourth quarter 2018) for each of the 15 scenarios. The hypothetical FMD outbreak was assumed to occur at the beginning of the first quarter of 2009.

The NOVAC scenario, the only scenario relying exclusively on animal destruction for disease control without any vaccination, has the largest total median producer plus consumer loss of any scenario and the longest median disease duration at nine quarters. The median cumulative loss to producers 
Table 4. Estimated 10-Year Producer Returns to Capital and Management and Consumer Surplus Impacts of Alternative Foot-and-Mouth Disease Control Scenarios for 10th, 50th, and 90th Disease Duration Percentiles

\begin{tabular}{|c|c|c|c|c|c|}
\hline \multirow[b]{2}{*}{$\begin{array}{l}\text { Scenario } \\
\text { Name }^{\mathrm{a}}\end{array}$} & \multirow[b]{2}{*}{$\begin{array}{l}\text { Disease } \\
\text { Duration } \\
\text { Percentile }\end{array}$} & \multirow[b]{2}{*}{$\begin{array}{l}\text { Disease } \\
\text { Duration } \\
\text { Quarters }\end{array}$} & \multicolumn{3}{|c|}{ Change in: } \\
\hline & & & $\begin{array}{l}\text { Returns to Capital } \\
\text { and Management } \\
\text { for Producers }\end{array}$ & $\begin{array}{l}\text { Consumer } \\
\text { Surplus } \\
\text { ion Dollars) }\end{array}$ & Total \\
\hline \multirow[t]{3}{*}{ NOVAC } & 10th & 1 & $-\$ 19,954$ & $\$ 3,501$ & $-\$ 16,453$ \\
\hline & 50th & 9 & $-\$ 93,366$ & $-\$ 94,406$ & $-\$ 187,773$ \\
\hline & 90th & 9 & $-\$ 93,295$ & $-\$ 95,252$ & $-\$ 188,547$ \\
\hline \multirow[t]{3}{*}{ D5/10/10 } & 10th & 1 & $-\$ 19,937$ & $\$ 3,491$ & $-\$ 16,446$ \\
\hline & 50 th & 7 & $-\$ 72,672$ & $-\$ 74,000$ & $-\$ 146,672$ \\
\hline & 90th & 9 & $-\$ 92,113$ & $-\$ 94,030$ & $-\$ 186,143$ \\
\hline \multirow[t]{3}{*}{$\mathrm{L} 5 / 10 / 10$} & 10th & 1 & $-\$ 23,920$ & $\$ 7,015$ & $-\$ 16,905$ \\
\hline & 50 th & 7 & $-\$ 78,274$ & $-\$ 68,455$ & $-\$ 146,729$ \\
\hline & 90 th & 9 & $-\$ 97,895$ & $-\$ 88,244$ & $-\$ 186,139$ \\
\hline \multirow[t]{3}{*}{ D1/10/10 } & 10th & 4 & $-\$ 50,765$ & $-\$ 41,579$ & $-\$ 92,344$ \\
\hline & 50th & 7 & $-\$ 78,112$ & $-\$ 68,449$ & $-\$ 146,562$ \\
\hline & 90th & 8 & $-\$ 87,425$ & $-\$ 72,943$ & $-\$ 160,368$ \\
\hline \multirow[t]{3}{*}{ D5/10/50 } & 10th & 1 & $-\$ 19,941$ & $\$ 3,512$ & $-\$ 16,429$ \\
\hline & 50 th & 3 & $-\$ 37,093$ & $-\$ 37,429$ & $-\$ 74,522$ \\
\hline & 90th & 4 & $-\$ 44,919$ & $-\$ 48,528$ & $-\$ 93,447$ \\
\hline \multirow[t]{3}{*}{$\mathrm{L} 5 / 10 / 50$} & 10th & 1 & $-\$ 23,925$ & $\$ 7,038$ & $-\$ 16,887$ \\
\hline & 50 th & 3 & $-\$ 42,053$ & $-\$ 32,524$ & $-\$ 74,576$ \\
\hline & 90th & 4 & $-\$ 49,921$ & $-\$ 43,711$ & $-\$ 93,631$ \\
\hline \multirow[t]{3}{*}{ D1/10/50 } & 10th & 3 & $-\$ 42,614$ & $-\$ 30,909$ & $-\$ 73,523$ \\
\hline & 50th & 5 & $-\$ 59,382$ & $-\$ 51,190$ & $-\$ 110,572$ \\
\hline & 90th & 7 & $-\$ 79,538$ & $-\$ 69,990$ & $-\$ 149,528$ \\
\hline \multirow[t]{3}{*}{ D5/100/10 } & 10 th & 2 & $-\$ 29,490$ & $-\$ 26,286$ & $-\$ 55,776$ \\
\hline & 50 th & 7 & $-\$ 72,545$ & $-\$ 74,667$ & $-\$ 147,213$ \\
\hline & 90th & 9 & $-\$ 92,149$ & $-\$ 93,149$ & $-\$ 185,299$ \\
\hline \multirow[t]{3}{*}{ L5/100/10 } & 10th & 2 & $-\$ 33,898$ & $-\$ 22,181$ & $-\$ 56,079$ \\
\hline & 50 th & 7 & $-\$ 78,149$ & $-\$ 69,121$ & $-\$ 147,270$ \\
\hline & 90th & 9 & $-\$ 97,940$ & $-\$ 87,363$ & $-\$ 185,302$ \\
\hline \multirow[t]{3}{*}{ D5/100/50 } & 10th & 2 & $-\$ 29,491$ & $-\$ 26,278$ & $-\$ 55,769$ \\
\hline & 50 th & 3 & $-\$ 37,109$ & $-\$ 37,434$ & $-\$ 74,544$ \\
\hline & 90th & 4 & $-\$ 44,974$ & $-\$ 48,397$ & $-\$ 93,371$ \\
\hline \multirow[t]{3}{*}{ L5/100/50 } & 10th & 2 & $-\$ 33,897$ & $-\$ 22,175$ & $-\$ 56,072$ \\
\hline & 50 th & 3 & $-\$ 41,803$ & $-\$ 32,911$ & $-\$ 74,714$ \\
\hline & 90th & 4 & $-\$ 49,982$ & $-\$ 43,567$ & $-\$ 93,549$ \\
\hline \multirow[t]{3}{*}{ D50/10/10 } & 10th & 1 & $-\$ 19,951$ & $\$ 3,523$ & $-\$ 16,428$ \\
\hline & 50 th & 6 & $-\$ 64,658$ & $-\$ 66,082$ & $-\$ 130,740$ \\
\hline & 90th & 9 & $-\$ 93,235$ & $-\$ 95,724$ & $-\$ 188,959$ \\
\hline \multirow[t]{3}{*}{ L50/10/10 } & 10 th & 1 & $-\$ 23,934$ & $\$ 7,051$ & $-\$ 16,882$ \\
\hline & 50th & 6 & $-\$ 69,995$ & $-\$ 60,659$ & $-\$ 130,654$ \\
\hline & 90th & 9 & $-\$ 97,836$ & $-\$ 87,859$ & $-\$ 185,695$ \\
\hline
\end{tabular}


Table 4. Continued.

\begin{tabular}{lllllll}
\hline \hline & & & \multicolumn{3}{c}{ Change in: } \\
\cline { 4 - 6 } & & & $\begin{array}{l}\text { Returns to Capital } \\
\text { and Management }\end{array}$ & $\begin{array}{l}\text { Consumer } \\
\text { Surplus }\end{array}$ & Total \\
Scenario & $\begin{array}{l}\text { Disease } \\
\text { Name }\end{array}$ & $\begin{array}{l}\text { Disease } \\
\text { Duration }\end{array}$ & $\begin{array}{l}\text { Duration } \\
\text { Qercentile }\end{array}$ & for Producers & $\begin{array}{l}\text { Suarters } \\
\text { (Million Dollars) }\end{array}$ & \\
\hline D50/10/50 & 10 th & 2 & $-\$ 29,558$ & $-\$ 26,131$ & $-\$ 55,689$ \\
& 50 th & 2 & $-\$ 29,578$ & $-\$ 25,952$ & $-\$ 55,529$ \\
& 90 th & 5 & $-\$ 53,447$ & $-\$ 57,622$ & $-\$ 111,070$ \\
L50/10/50 & 10th & 2 & $-\$ 33,966$ & $-\$ 22,025$ & $-\$ 55,991$ \\
& 50 th & 2 & $-\$ 33,990$ & $-\$ 21,839$ & $-\$ 55,829$ \\
& 90 th & 5 & $-\$ 58,759$ & $-\$ 52,450$ & $-\$ 111,209$ \\
\hline \hline
\end{tabular}

${ }^{\text {a }}$ Scenario names are as defined in Table 1.

and consumers for the NOVAC scenario is $\$ 187.8$ billion. In addition to the producer and consumer losses, estimated median government costs for the NOVAC scenario are $\$ 11.5$ billion (Table 5), which is associated with animal depopulation costs (euthanasia, indemnity payments, disposal costs, and cleaning and disinfecting).

Our loss estimates are much larger than those in studies focused on short-run localized FMD outbreaks that generally lasted less than two quarters (Elbakidze et al., 2009; Hagerman et al., 2012; Pendell et al., 2007). However, the economic losses estimated here are consistent with those estimated by the U.S. Department of Homeland Security (2012), which used an eight-state (Arkansas, Colorado, Iowa, Kansas, Missouri, Nebraska, Oklahoma, and Texas) epidemiology disease simulation model representing a similar geographic region to our area (Colorado, Kansas, Nebraska, northern New Mexico, northern Oklahoma, South Dakota, panhandle of Texas, and Wyoming).

Median losses to producers and consumers and government costs for NOVAC are similar to the 90th percentile losses (Figure 1) indicating a highly skewed distribution of probable losses with a high probability of large losses under this scenario. This is an important finding because it demonstrates that expected economic loss distributions are not symmetric around the median, which is due to an asymmetric disease spread probability distribution. There is a high probability that an FMD outbreak similar to that introduced in this study under NOVAC would result in domestic combined consumer and producer losses approaching $\$ 188$ billion and direct government costs near $\$ 11$ billion. Without utilizing a vaccination plan, there is a small chance that the disease would be rapidly controlled during the first quarter of the outbreak and producer and consumer losses curtailed at $\$ 16$ billion and government costs at $\$ 57$ million at the lower 10th percentile level of the disease duration (Tables 4 and 5). 
Table 5. Government Costs for 10th, 50th, and 90th Disease Duration Percentiles under Various Scenarios

\begin{tabular}{|c|c|c|c|c|c|c|c|}
\hline \multirow{2}{*}{$\begin{array}{l}\text { Scenario } \\
\text { Name }^{\mathrm{a}}\end{array}$} & \multirow{2}{*}{$\begin{array}{l}\text { Disease } \\
\text { Duration } \\
\text { Percentile }\end{array}$} & \multicolumn{6}{|c|}{ Government Costs (Million Dollars) } \\
\hline & & Cow-Calf & Feedlot & Dairy & Swine & Sheep & Total \\
\hline \multirow[t]{3}{*}{ NOVAC } & 10th & $\$ 0.0$ & $\$ 41.3$ & $\$ 15.2$ & $\$ 0.0$ & $\$ 0.0$ & $\$ 56.5$ \\
\hline & 50th & $\$ 463.1$ & $\$ 8,265.9$ & $\$ 2,138.8$ & $\$ 617.8$ & $\$ 13.9$ & $\$ 11,499.5$ \\
\hline & 90th & $\$ 517.3$ & $\$ 8,308.4$ & $\$ 2,128.7$ & $\$ 669.6$ & $\$ 21.0$ & $\$ 11,645.0$ \\
\hline \multirow{3}{*}{$\mathrm{D} 5 / 10 / 10$} & 10th & $\$ 0.1$ & $\$ 20.2$ & $\$ 0.0$ & $\$ 0.0$ & $\$ 0.0$ & $\$ 20.2$ \\
\hline & 50 th & $\$ 52.2$ & $\$ 7,526.9$ & $\$ 599.5$ & $\$ 103.9$ & $\$ 0.6$ & $\$ 8,283.1$ \\
\hline & 90th & $\$ 55.8$ & $\$ 7,872.2$ & $\$ 619.6$ & $\$ 101.3$ & $\$ 1.3$ & $\$ 8,650.3$ \\
\hline \multirow[t]{3}{*}{$\mathrm{L} 5 / 10 / 10$} & 10th & $\$ 0.1$ & $\$ 20.2$ & $\$ 0.0$ & $\$ 0.0$ & $\$ 0.0$ & $\$ 20.2$ \\
\hline & 50 th & $\$ 52.2$ & $\$ 7,526.9$ & $\$ 599.5$ & $\$ 103.9$ & $\$ 0.6$ & $\$ 8,283.1$ \\
\hline & 90th & $\$ 53.4$ & $\$ 7,872.2$ & $\$ 610.0$ & $\$ 93.5$ & $\$ 1.3$ & $\$ 8,630.5$ \\
\hline \multirow[t]{3}{*}{ D1/10/10 } & 10th & $\$ 71.6$ & $\$ 6,806.5$ & $\$ 563.2$ & $\$ 104.3$ & $\$ 1.6$ & $\$ 7,547.2$ \\
\hline & 50 th & $\$ 41.4$ & $\$ 7,543.8$ & $\$ 415.6$ & $\$ 92.3$ & $\$ 1.1$ & $\$ 8,094.2$ \\
\hline & 90th & $\$ 39.3$ & $\$ 7,578.6$ & $\$ 486.3$ & $\$ 51.7$ & $\$ 1.3$ & $\$ 8,157.2$ \\
\hline \multirow[t]{3}{*}{ D5/10/50 } & 10th & $\$ 0.1$ & $\$ 62.1$ & $\$ 0.0$ & $\$ 0.0$ & $\$ 0.0$ & $\$ 62.2$ \\
\hline & 50 th & $\$ 18.3$ & $\$ 2,289.6$ & $\$ 95.8$ & $\$ 22.5$ & $\$ 0.1$ & $\$ 2,426.4$ \\
\hline & 90th & $\$ 16.0$ & $\$ 2,187.6$ & $\$ 78.8$ & $\$ 13.9$ & $\$ 0.1$ & $\$ 2,296.3$ \\
\hline \multirow[t]{3}{*}{$\mathrm{L} 5 / 10 / 50$} & 10th & $\$ 0.1$ & $\$ 62.1$ & $\$ 0.0$ & $\$ 0.0$ & $\$ 0.0$ & $\$ 62.2$ \\
\hline & 50 th & $\$ 18.3$ & $\$ 2,289.6$ & $\$ 95.8$ & $\$ 22.5$ & $\$ 0.1$ & $\$ 2,426.4$ \\
\hline & 90th & $\$ 16.0$ & $\$ 2,187.6$ & $\$ 78.8$ & $\$ 13.9$ & $\$ 0.1$ & $\$ 2,296.3$ \\
\hline \multirow[t]{3}{*}{ D1/10/50 } & 10th & $\$ 55.3$ & $\$ 6,310.0$ & $\$ 610.8$ & $\$ 138.1$ & $\$ 2.0$ & $\$ 7,116.2$ \\
\hline & 50 th & $\$ 36.1$ & $\$ 5,838.5$ & $\$ 496.2$ & $\$ 113.5$ & $\$ 0.5$ & $\$ 6,484.8$ \\
\hline & 90th & $\$ 154.6$ & $\$ 7,712.4$ & $\$ 2,144.7$ & $\$ 654.1$ & $\$ 0.2$ & $\$ 10,666.0$ \\
\hline \multirow[t]{3}{*}{ D5/100/10 } & 10th & $\$ 0.3$ & $\$ 120.9$ & $\$ 1.6$ & $\$ 11.9$ & $\$ 0.0$ & $\$ 134.7$ \\
\hline & 50 th & $\$ 61.2$ & $\$ 7,477.2$ & $\$ 520.9$ & $\$ 96.7$ & $\$ 4.2$ & $\$ 8,160.3$ \\
\hline & 90th & $\$ 48.1$ & $\$ 7,905.8$ & $\$ 580.2$ & $\$ 104.7$ & $\$ 0.8$ & $\$ 8,639.6$ \\
\hline \multirow[t]{3}{*}{ L5/100/10 } & 10th & $\$ 0.3$ & $\$ 120.9$ & $\$ 1.6$ & $\$ 11.9$ & $\$ 0.0$ & $\$ 134.7$ \\
\hline & 50th & $\$ 61.1$ & $\$ 7,477.2$ & $\$ 520.9$ & $\$ 94.2$ & $\$ 4.2$ & $\$ 8,157.7$ \\
\hline & 90th & $\$ 48.1$ & $\$ 7,905.8$ & $\$ 580.2$ & $\$ 104.7$ & $\$ 0.8$ & $\$ 8,639.6$ \\
\hline \multirow[t]{3}{*}{ D5/100/50 } & 10th & $\$ 1.9$ & $\$ 124.7$ & $\$ 0.0$ & $\$ 0.0$ & $\$ 0.0$ & $\$ 126.6$ \\
\hline & 50 th & $\$ 16.8$ & $\$ 2,521.9$ & $\$ 98.0$ & $\$ 39.7$ & $\$ 0.3$ & $\$ 2,676.7$ \\
\hline & 90th & $\$ 8.1$ & $\$ 2,568.6$ & $\$ 108.4$ & $\$ 15.3$ & $\$ 0.4$ & $\$ 2,700.8$ \\
\hline \multirow[t]{3}{*}{ L5/100/50 } & 10th & $\$ 1.9$ & $\$ 124.7$ & $\$ 0.0$ & $\$ 0.0$ & $\$ 0.0$ & $\$ 126.6$ \\
\hline & 50 th & $\$ 16.8$ & $\$ 2,521.9$ & $\$ 98.0$ & $\$ 39.7$ & $\$ 0.3$ & $\$ 2,676.7$ \\
\hline & 90th & $\$ 8.1$ & $\$ 2,568.6$ & $\$ 108.4$ & $\$ 15.3$ & $\$ 0.4$ & $\$ 2,700.8$ \\
\hline \multirow[t]{3}{*}{ D50/10/10 } & 10th & $\$ 12.8$ & $\$ 85.7$ & $\$ 7.0$ & $\$ 0.1$ & $\$ 0.3$ & $\$ 105.8$ \\
\hline & 50 th & $\$ 348.5$ & $\$ 8,057.2$ & $\$ 2,261.7$ & $\$ 534.1$ & $\$ 8.6$ & $\$ 11,210.1$ \\
\hline & 90th & $\$ 3,720.7$ & $\$ 7,674.7$ & $\$ 2,198.7$ & $\$ 1,215.8$ & $\$ 3.7$ & $\$ 14,813.6$ \\
\hline \multirow[t]{3}{*}{ L50/10/10 } & 10th & $\$ 1.3$ & $\$ 85.7$ & $\$ 6.6$ & $\$ 0.0$ & $\$ 0.0$ & $\$ 93.6$ \\
\hline & 50 th & $\$ 231.0$ & $\$ 8,057.2$ & $\$ 2,120.0$ & $\$ 426.8$ & $\$ 6.5$ & $\$ 10,841.4$ \\
\hline & 90th & $\$ 131.1$ & $\$ 7,674.7$ & $\$ 547.0$ & $\$ 179.7$ & $\$ 1.6$ & $\$ 8,534.0$ \\
\hline \multirow[t]{3}{*}{ D50/10/50 } & 10th & $\$ 2.0$ & $\$ 591.2$ & $\$ 51.3$ & $\$ 2.5$ & $\$ 0.0$ & $\$ 647.0$ \\
\hline & 50 th & $\$ 4.7$ & $\$ 1,080.0$ & $\$ 46.0$ & $\$ 5.8$ & $\$ 0.0$ & $\$ 1,136.5$ \\
\hline & 90 th & $\$ 9.3$ & $\$ 2,237.8$ & $\$ 116.7$ & $\$ 4.2$ & $\$ 0.1$ & $\$ 2,368.1$ \\
\hline \multirow[t]{3}{*}{ L50/10/50 } & 10th & $\$ 2.0$ & $\$ 591.2$ & $\$ 51.3$ & $\$ 2.5$ & $\$ 0.0$ & $\$ 647.0$ \\
\hline & 50 th & $\$ 4.7$ & $\$ 1,080.0$ & $\$ 46.0$ & $\$ 5.8$ & $\$ 0.0$ & $\$ 1,136.5$ \\
\hline & 90th & $\$ 9.3$ & $\$ 2,237.8$ & $\$ 116.7$ & $\$ 4.2$ & $\$ 0.1$ & $\$ 2,368.1$ \\
\hline
\end{tabular}

ascenario names are as defined in Table 1. 
Producers and consumers would roughly share losses equally under a NOVAC scenario unless the outbreak was very short lived, in which case losses would accrue to producers with an increase in surplus for consumers. The increased consumer surplus under a low-probability short-duration outbreak is a result of closure of the export market for beef and pork reducing domestic retail prices.

\subsection{Vaccination Strategy}

Emergency vaccination strategies offer considerable opportunity to impact both the median economic losses and alter the distribution of expected losses. Scenario D5/10/10 - which is a vaccinate to die (D), has 5 herds per day and 10 herds per day vaccination capacity at days 22 and 40 (5), respectively; employs an emergency vaccinate-to-die program with a $10 \mathrm{~km}$ vaccination zone around infected herds (10); and has a 10-herd trigger to vaccinate (10) (Table 1)results in a $\$ 146.7$ billion median total loss to producers and consumers and an $\$ 8.3$ billon government cost, more than a $20 \%$ reduction relative to the NOVAC scenario (Tables 4 and 5). D5/10/10 results in an outbreak at the median that lasts seven quarters, two less than the NOVAC scenario. However, the 10th and 90th percentile confidence intervals of losses for D5/10/10 are similar to those for NOVAC (Figure 1). Emergency vaccination strategies greatly reduce the expected adverse economic impact of an FMD outbreak. However, as discussed subsequently, the vaccination scheme and associated vaccination capacity constraints have substantial impacts on the estimated economic outcomes.

\subsection{Vaccinate to Live versus Die}

Whether a vaccinate-to-die (D5/10/10) or a vaccinate-to-live (L5/10/10) strategy is used does not have a large impact on median total producer and consumer losses (though the losses are redistributed some among the two) or on government costs. Similar economic impacts are also evident in other scenarios in which the only difference is vaccinating to die or live (e.g., scenario D5/10/50 vs. L5/10/50, D5/100/10 vs. L5/100/10, D5/100/50 vs. L5/100/50, D50/10/10 vs. L50/10/10, and D50/10/50 vs. L50/10/50). ${ }^{7}$ This result is conditional on the way we have modeled the vaccination strategies in this study. For most scenarios, vaccination capacity constraints resulted in primarily cattle from large feedlots only being vaccinated.

Vaccinating to live versus to die has different implications from an international trade perspective in that under vaccinate-to-live scenarios, export market access would likely be delayed at least one additional quarter relative

7 An important difference in scenarios D50/10/10 and L50/10/10, in contrast to the other scenarios that only differ from each other on vaccinating to die versus live, is that for the upper 90th percentile in these two scenarios larger differences in government costs are present across these scenarios. At the upper end of the distribution, many more animals other than fed cattle end up being vaccinated to live in scenario L50/10/10, resulting in reduced government costs for indemnification relative to D50/10/10. 
to a vaccinate-to-die scenario. In the economic model, we assumed $95 \%$ reduction in export market access endured one quarter after the duration of the disease for vaccinate-to-die scenarios and two quarters after the duration for vaccinate-to-live scenarios before gradually recovering export market access (as described previously). As such, producer losses are greater under vaccinate-tolive scenarios, and consumer losses are less because the lost export market for an additional quarter is detrimental to livestock market prices increasing producer losses and reducing domestic consumer prices of meat.

Scenarios D5/10/10 and L5/10/10 have similar numbers of animals destroyed (Appendix A), expected disease durations, and overall economic impacts (Table 4). In our scenarios, we assumed feedlot animals that were vaccinated to die or live would be slaughtered in commercial slaughter facilities within a year and that an indemnity payment would not be paid by the government. For others, we assumed animals vaccinated to die did not enter commercial meat production and were destroyed by government and that an indemnity payment was paid by government the year they were vaccinated to die. No animals vaccinated to live were destroyed or warranted an indemnity payment by government. One potential difference between a vaccinate-to-die versus vaccinate-to-live scenario would be possible slaughter capacity constraints to kill fed cattle vaccinated to die in a timely manner-a constraint that is not part of our analysis.

Two strategies that stand out somewhat relative to vaccinating are those in which vaccination capacity was limited to one herd per day by 22 days after disease detection and three herds per day by 40 days after disease detection (D1/10/10 and D1/10/50). In these two scenarios, we reduced the vaccination capacity relative to similar respective scenarios D5/10/10 and L5/10/10 (relative to $\mathrm{D} 1 / 10 / 10$ ), and $\mathrm{D} 5 / 10 / 50$ and L5/10/50 (relative to D1/10/50). Despite the lower vaccination capacity, scenario D1/10/10 results in similar median consumer and producers losses (\$146.6 billion) compared with D5/10/10 and L5/10/10 (those with the same vaccination trigger and zone size). Scenario D1/10/10 results in similar median government costs to D5/10/10 and L5/10/10 (Table 5). However, because all three of these scenarios have relatively small vaccination zones $(10 \mathrm{~km})$, they result in much larger losses than corresponding scenarios D5/10/50, L5/10/50, and D1/10/50 (all sharing the same 10-herd vaccination trigger) where the vaccination zones are increased to $50 \mathrm{~km}$.

Scenario D1/10/50 has two-quarter-longer median and 10th percentile and three-quarter-longer 90th percentile duration than D5/10/50 and L/5/10/50 (scenarios with the same trigger and vaccination zones). As such, D1/10/50 has a larger median loss ( $\$ 111$ billion compared with $\$ 75$ billion) as well as larger 10th and 90th percentile losses (Table 4). This scenario results in larger losses because the vaccination capacity is smaller. With a limited vaccination capacity, the vaccination rate is slower and the disease persists longer. Deploying a limited-capacity vaccination strategy results in longer disease duration and larger economic cost than more aggressive emergency vaccination protocols. 
However, a limited-capacity vaccination strategy results in lower economic costs compared with the baseline depopulation strategy (NOVAC).

Comparing the two very low-capacity vaccination strategies, D1/10/10 and D1/10/50, suggests that increasing the vaccination zone under this strategy from $10 \mathrm{~km}$ to $50 \mathrm{~km}$ reduces median losses to consumers and producers by $\$ 36$ billion (25\% reduction) and government costs by approximately $\$ 1.6$ billion ( $20 \%$ reduction). In D1/10/50, the vaccination capacity constraint resulted in less benefit from expanding the vaccination zone from $10 \mathrm{~km}$ to $50 \mathrm{~km}$ compared with scenarios D5/10/10 and D5/10/50 in which the vaccination capacity was much larger. More analysis is needed on how the capacity constraint would affect overall economic impacts. Our scenarios targeted large feedlots as the highest vaccination priority. This results in vaccination capacity rapidly becoming a binding constraint.

\subsection{Size of Vaccination Zone}

The vaccination zone was simulated using two different values of $10 \mathrm{~km}$ and $50 \mathrm{~km}$ to contrast how the size of the zone impacts producers and consumers in the wake of an FMD outbreak. Comparing strategies that differ only in vaccination zone size reveals the marked economic importance of this disease response component.

For example, consider scenario D5/10/10 versus D5/10/50; both are vaccinateto-die strategies with the same vaccination capacity and trigger (Table 1), but D5/10/10 has a $10 \mathrm{~km}$ vaccination zone compared with a $50 \mathrm{~km}$ zone for D5/10/50. At the medians, approximately 10 million more animals are vaccinated in D5/10/50, with approximately 7.5 million fewer animals depopulated. This illustrates the trade-off of increasing vaccination zone size. As a result, producer and consumer losses are much smaller when the vaccination zone is $50 \mathrm{~km}$ compared with $10 \mathrm{~km}$. The median loss under $10 \mathrm{~km}(\mathrm{D} 5 / 10 / 10)$ is $\$ 147$ billion compared with about half that for the $50 \mathrm{~km}$ zone (D5/10/50) of $\$ 75$ billion. Similar results are revealed comparing other scenarios that differ only by vaccination zone (e.g., scenarios L5/10/10 vs. L5/10/50, D1/10/10 vs. D1/10/50, D5/100/10 vs. D5/100/50, L5/100/10 vs. L5/100/50, D50/10/10 vs. D50/10/50, and L50/10/10 vs. L50/10/50). In each of these comparisons, total returns to capital and management for producers and consumer median surplus losses decline by more than $\$ 70$ billion when the vaccination zone increases from $10 \mathrm{~km}$ to $50 \mathrm{~km}$ (except D1/10/10 and D1/10/50 where vaccine capacity is severely limited and total losses decline by about half that amount at $\$ 36$ billion, which, as noted previously, is smaller because of the vaccination capacity constraint).

Expanding the vaccination zone from $10 \mathrm{~km}$ to $50 \mathrm{~km}$ results in more than doubling the median number of animals that would be vaccinated with the exception of when vaccination capacity is expanded from 5 herds per day by day 22 and 10 herds per day by day 40 to 50 herds per day and 80 herds per 
day (discussed more subsequently). For example, in scenario D5/10/10 with a $10 \mathrm{~km}$ zone, a total of 7.8 million head of animals are vaccinated compared with 18.0 million for D5/10/50 with a $50 \mathrm{~km}$ zone (Appendix A). Similarly, scenario D5/100/10 results in 7.3 million head vaccinated compared with 15.3 million head for D5/100/50. As such, government costs of vaccinating more than double with expanded vaccination zones, but government costs savings due to lower indemnity payments more than offset vaccination cost increases resulting in overall government cost savings of some $\$ 5$ billion or more (Table 5).

For each scenario comparison, D5/10/10 versus D5/10/50, L5/10/10 versus L5/10/50, D5/100/10 versus D5/100/50, and L5/100/10 versus L5/100/50, government costs decline $\$ 5.5$ billion to $\$ 6$ billion when the vaccination zone increases from $10 \mathrm{~km}$ to $50 \mathrm{~km}$. However, government costs do not decline when the zone is increased from $10 \mathrm{~km}$ to $50 \mathrm{~km}$ for very low vaccine capacity (scenario $\mathrm{D} 1 / 10 / 10$ vs. D1/10/50). This is because vaccination capacity is not sufficient to take advantage of the larger vaccination zone, so little effect is realized.

If vaccination capacity is expanded from 5 and 10 herds per day to 50 and 80 herds per day (Table 1 ) on days 22 and 40 , the size of the vaccination zone has even more dramatic government cost savings (see, e.g., scenarios D50/10/10 and D50/10/50, both vaccinate to die with 50 and 80 herds per day vaccination capacities, but $10 \mathrm{~km}$ vs. $50 \mathrm{~km}$ vaccination zones, respectively). Under a 50 - and 80-herd-per-day vaccination plan, producers and private veterinarians would have to administer much of the vaccination themselves because animal health officials would not be able to accomplish this rate of vaccination. ${ }^{8}$ We assume that sufficient stocks of vaccine could be generated in response to an FMD outbreak. Vaccination capacity in the model increases over 40 days from the initiation of the vaccination program allowing substantial time to increase production. The high-capacity vaccination schemes in our model, even at the 90th percentile, are smaller than the average vaccination rate of 350,000 head of cattle per day in each round of vaccination in the 2001 Uruguay outbreak (Sutmoller et al., 2003). As such, the vaccination scheme we assume in our model should be achievable.

Scenario D50/10/50 results in $\$ 75$ billion smaller median producer and consumer losses and approximately $\$ 10$ billion government cost savings compared with D50/10/10. Comparing D5/10/50 (vaccination capacity 5 and 10) with $\mathrm{D} 50 / 10 / 50$ (vaccination capacity 50 and 80 ), both with a $50 \mathrm{~km}$ vaccination zone, median producer and consumer losses are $\$ 19$ billion lower and government costs are $\$ 1.3$ billion lower for D/50/10/50. In contrast, the 10th and 90th percentiles for producer and consumer losses and government costs are lower for D5/10/50. So, larger vaccination zones appear warranted based on returns to capital and management for producers and consumer

8 For cost estimates, we treated both the 5,10 and 50, 80 vaccination plans assuming the government administered the vaccinations. 
surplus savings plus government cost savings; however, the value of increased vaccination capacity is less clear. A high-capacity vaccination strategy would necessitate sufficient government stocks for a large-scale FMD vaccination program and require a change in current preferences that FMD vaccinations only be administered by a licensed animal health official. Although beyond the scope of this study, it is noteworthy that animal health officials face numerous tradeoffs between making investments to be prepared in advance of a potential disease event relative to decisions made during an event (Elbakidze and McCarl, 2006).

\subsection{Vaccination Trigger}

The vaccination trigger refers to the number of herds that are infected before an emergency vaccination program is implemented. Because of the costs associated with vaccinating, both direct costs of the physical activity as well as irreversible trade implications of an FMD vaccination scheme, avoiding any vaccination altogether is preferable. However, delaying vaccination increases risks of rapid disease spread if a widespread epidemic appears probable.

Two vaccination triggers were assessed in this study, after 10 herds were detected and after 100 herds were detected. We estimate the impact of altering the trigger under two different vaccination size zones $(10 \mathrm{~km}$ and $50 \mathrm{~km})$ as there might be interaction between the vaccination trigger and vaccination size zone. Results reveal that the losses associated with an FMD outbreak are not sensitive to the vaccination trigger for the two levels selected. For example, scenarios D5/10/10 and D5/100/10, which differ only by the trigger (Table 1 ), result in similar median losses to producers and consumers (Table 4) and government costs (Table 5). The smaller vaccination trigger does have smaller 10th percentile government costs and producer and consumer losses, which is not surprising because under a well-contained disease event that is short lived, keeping the trigger small would reduce overall costs. The effect of the vaccination trigger is similar in other scenarios that differ only by herd trigger (e.g., L5/10/10 and L5/100/10, D5/10/50 and D5/100/50, and L5/10/50 and L5/100/50). As such, the vaccination trigger employed by animal health officials during an FMD outbreak appears not to be a major determinant of economic losses that would likely result unless the disease were very rapidly contained through stamping out.

\section{Conclusions}

In the event of an FMD outbreak, because the disease is so highly contagious and can spread quickly, animal health officials need to be prepared with disease mitigation plans in place. Under such a disease outbreak, numerous factors are within the control of animal health officials. Although rapid control of the disease is the obvious goal, equally essential in developing disease management plans is to understand the economic impacts of alternative strategies. This study estimated the economic impact on producers and consumers and selected government 
costs associated with alternative FMD disease management strategies for a given hypothetical disease introduced in a northeast Colorado cattle feedlot. Particular emphasis was placed on estimating the impacts of alternative emergency vaccination protocols. Large feedlots were the priority for vaccination in the scenarios reported here. Due to vaccine capacity constraints, in all scenarios but two (D50/10/10 and L50/10/10), only or predominantly feedlot cattle were vaccinated. As such, results here are relevant to economic impact when primarily feedlot cattle are vaccinated. Further evaluation of alternate vaccination priorities is needed.

An FMD outbreak similar to that simulated here would be expected to result in approximately $\$ 188$ billion in losses to producers and consumers and $\$ 11$ billion in government costs if control relied exclusively on movement control, biosecurity, and stamping out with no emergency vaccination program implemented. At the other extreme, the most optimistic median economic impact would be to deploy an aggressive emergency vaccination program that would cover a $50 \mathrm{~km}$ vaccination zone around infected herds and have a large rate of herd vaccination at 22 days ( 50 herds per day) and 40 days ( 80 herds per day). This response would require producers to engage in conducting vaccinations without animal health officials on-site, a strategy not generally supported by U.S. animal health officials. Such a response would significantly reduce the median economic impact to a $\$ 56$ billion loss to producers and consumers and a $\$ 1.1$ billion government cost.

An aggressive vaccination strategy, however, results in substantially greater losses to producers and consumers (approximately $\$ 30$ billion more) if the disease were able to be rapidly contained (e.g., 10th percentile lower tail of the distribution) through stamping out or less aggressive vaccination programs (10th percentile for scenarios D5/10/50 and L5/10/50). The likelihood of very rapid containment of an FMD outbreak is small, but we need to be cognizant of this important trade-off. Decision criteria that animal health officials might be able to use to distinguish outbreaks that can be contained quickly through stamping out from outbreaks that are likely to become larger and longer lasting and would benefit from emergency vaccination would be valuable.

Previous studies have suggested that emergency vaccination programs, mostly because of their impacts on trade, should only be deployed if the probability of major disease spread is high (see Mahul and Gohin, 1999). Our findings suggest that, at least in the Midwest region of the United States, the chances of an FMD outbreak becoming a widespread epidemic are high, and consistent with the U.S. Department of Homeland Security (2012), certainly involving more animals and geographic regions than regional model results (Elbakidze et al., 2009; Hagerman et al., 2012; Pendell et al., 2007). Previous studies focused on smaller regional FMD outbreak geographic areas had more limited susceptible animal populations to be infected relative to our larger geographic area. Our larger area is more difficult to control, which results in much larger epidemiological 
outbreaks. The implication is that aggressive interventions including vaccination to mitigate the spread of disease are more strongly justified for larger, more realistic disease spread regions.

Deploying an emergency vaccination program in light of an FMD outbreak would be expected to result in significant savings to producers and consumers and could save government costs as well. However, the nature of the emergency vaccination program that government health officials might deploy has substantial expected economic impact. Of the two major drivers of economic impact, vaccination zone and vaccination trigger, vaccination zone size is more important than the vaccination trigger for the alternatives compared in this study. Increasing the vaccination zone from $10 \mathrm{~km}$ to $50 \mathrm{~km}$ reduces producer and consumer median losses by approximately $\$ 70$ billion (approximately $48 \%$ savings) with an additional $\$ 15$ billion savings (approximately 10\%) being associated with increasing the vaccination capacity from 5 herds per day in 22 days and 10 herds per day in 40 days to 50 and 80 herds per day in 22 and 40 days, respectively. This higher vaccination capacity likely represents a situation in which producers would be allowed to vaccinate their own herds.

Vaccination strategies that do not have as much economic impact, given our modeling approach, include whether animals are vaccinated to live or die, the vaccination trigger, and very low vaccination capacity. However, these findings are conditional on our binding vaccination capacity constraints and prioritizations of vaccinating large feedlot cattle first, which generally exhausted vaccination capacity. Median losses are not substantially impacted by altering these characteristics. However, implementation of some of these strategies appears to substantially alter the distribution of potential economic losses, truncating both the lower and upper tails of the distribution of losses, though generally the truncation is much larger on the lower loss tail than on the upper loss tail and median losses do not improve much.

As with any study, several limitations of this work are particularly noteworthy. All of the modeling in this study is based on simulations. The disease outbreak simulated is hypothetical because such an event has not occurred in modern times in the United States. As such, we simply do not know where the disease might be introduced, and we do not know exactly how the disease spread might occur. Undoubtedly, disease mitigation strategies deployed by animal health officials would be endogenous as such an event unfolded. We assumed fixed mitigation strategies and simulated stochastic disease spread. Very important to the economic impact assessment is the duration of the disease and assumed domestic and export market demand impacts. There is little published information on how domestic or export markets would react to such a disease outbreak. The United States realized export market closures associated with the bovine spongiform encephalopathy, but beyond that and OIE stipulations, there is scant information from which to anticipate demand shocks under such an event. Such limitations are important to note as the results of this study are 
considered. We presumed that export markets would gradually begin to recover and would fully recover in two years following eradication of the disease.

This study raises a number of questions for future research. The scenarios analyzed here were limited in the number of different types and levels of vaccination strategies and assumption and constraints imposed. An unlimited combination of alternative levels of vaccination capacities, triggers, size zones, whether to vaccinate to die or live, and other strategies could be evaluated. Most promising might be to continue to assess vaccination zone and vaccination capacity constraints. The less limiting these are, the less the economic impact of an FMD outbreak. However, there are clear trade-offs with such strategies. Because losses would be lower without vaccinating at all in a rapidly contained outbreak, continuing to explore ways to more rapidly contain such an outbreak remains a potentially valuable endeavor, as well as exploring methods to distinguish early in the course of an outbreak those that are coming under control from those that are expanding and in need of more aggressive intervention. Another area that needs more work is gaining a better understanding of probable domestic consumer demand and export market impacts associated with such disease events. Like previous studies, we have made assumptions about these impacts that are based on judgment from a few observed events around the world. However, gaining a better understanding of probable domestic and international demand impacts is worthwhile given the large impact they have on economic outcomes. Finally, sensitivity analysis around the economic parameters of the model is worth exploring in future work.

\section{References}

Armbruster, W.J. "Partnerships for Risk Communications: Environmental, Agricultural, and Food Issues." Environmental Communication in the Information Society-Proceedings of the 16th Conference. W. Pillmann and K. Tochtermann, eds. Vienna, Austria: IGU/ISEP, 2002.

Barnett, P., A.J.M. Garland, R.P. Kitching, and C.G. Schermbrucker. "Aspects of Emergency Vaccination against Foot-and-Mouth Disease." Comparative Immunology, Microbiology and Infectious Diseases 25(2002):345-64.

Burrell, A.M., and M.-J. Mangen. "Animal Disease Epidemics: To Vaccinate or Not to Vaccinate?” EuroChoices 1(April 2001):24-27.

Ekboir, J., L.S. Jarvis, D.A. Sumner, J.E. Bervejillo, and W.R. Sutton. "Changes in Foot and Mouth Disease Status and Evolving World Beef Markets." Agribusiness 18,2(2002):213-29.

Elbakidze, L., L. Highfield, M. Ward, B.A. McCarl, and B. Norby. "Economics Analysis of Mitigation Strategies for FMD Introduction in Highly Concentrated Animal Feeding Regions.” Review of Agricultural Economics 31,4(2009):931-50.

Elbakidze, L., and B.A. McCarl. "Animal Disease Pre-Event Preparedness versus Post-Event Response: When Is It Economic to Protect?” Journal of Agricultural and Applied Economics 38,2(August 2006):327-36. 
Grubman, M.J., and B. Baxt. "Foot-and-Mouth Disease." Clinical Microbiology Reviews 17,2(2004):465-93.

Hagerman, A.D., B.A. McCarl, T.E. Carpenter, M.P. Ward, and J. O’Brien. “Emergency Vaccination to Control Foot-and-Mouth Disease: Implications of Its Inclusion as a U.S. Policy Option." Applied Economic Perspectives and Policy 34,1(2012):11946.

Harvey, N., A. Reeves, M.A. Schoenbaum, F.J. Zagmutt-Vergara, C. Dubé, A.E. Hill, B.A. Corso, W.B. McNab, C.I. Cartwright, and M.D. Salman. "The North American Animal Disease Spread Model: A Simulation Model to Assist Decision Making in Evaluating Animal Disease Incursions.” Preventive Veterinary Medicine 82(December 2007):176-97.

Mahul, O., and A. Gohin. "Irreversible Decision Making in Contagious Animal Disease Control under Uncertainty: An Illustration using FMD in Brittany." European Review of Agricultural Economics 26,1(1999):39-58.

Mangen, M.-J., M. Nielen, and A.M. Burrell. "Simulated Effect of Pig-Population Density on Epidemic Size and Choice of Control Strategy for Classical Swine Fever Epidemics in The Netherlands." Preventive Veterinary Medicine 56(2002):14163.

McReynolds, S.W., M.W. Sanderson, A. Reeves, M. Sinclair, A.E. Hill, and M.D. Salmon. "Direct and Indirect Contact Rates among Livestock Operations in Colorado and Kansas.” Journal American Veterinary Medical Association 244,9(May 2014):106674.

Melius, C., A. Robertson, and P. Hullinger. Developing Livestock Facility Type Information from USDA Agricultural Census Data for Use in Epidemiological and Economic Models. Livermore, CA: Lawrence Livermore National Laboratory, UCRL-TR-226008, November 10, 2006.

Miller, L.P., and M. Gallagher. Personal Communication. U.S. Department of Agriculture, Animal and Plant Health Inspection Service, 2010.

Niemi, J.K., and H. Lehtonen. "Modelling Pig Sector Dynamic Adjustment to Livestock Epidemics with Stochastic-Duration Trade Disruptions." European Review of Agricultural Economics 38,4(2011):529-51.

Nogueira, L., T.L. Marsh, P.R. Tozer, and D. Peel. "Foot-and-Mouth Disease and the Mexican Cattle Industry.” Agricultural Economics 42,s1(2011):33-44.

Paarlberg, P.L., and J.G. Lee. "Import Restrictions in the Presence of a Health Risk: An Illustration Using FMD." American Journal of Agricultural Economics 80(February 1998):175-83.

Paarlberg, P.L., J.G. Lee, and A.H. Seitzinger. "Measuring Welfare Effects of an FMD Outbreak in the United States." Journal of Agricultural and Applied Economics 35,1(April 2003):53-65.

- . "Potential Revenue Impact of an Outbreak of Foot-and-Mouth Disease in the United States." Journal of the American Veterinary Medical Association 220,7(April 2002):988-92.

Paarlberg, P.L., A.H. Seitzinger, J.G. Lee, and K.H. Mathews Economic Impacts of Foreign Animal Disease. Washington, DC: U.S. Department of Agriculture, Economic Research Report No. 57, May 2008.

- . " "Supply Reductions, Export Restrictions, and Expectations for Hog Returns in a Potential Classical Swine Fever Outbreak in the United States." Journal of Swine Health Production 17,3(2009):155-62. 
Parent, K.B., G.Y. Miller, and P.J. Hullinger. "Triggers for Foot and Mouth Disease Vaccination in the United States." Revue Scientifique et Technique 30,3(2011):78996.

Pendell, D.L., J. Leatherman, T.C. Schroeder, and G.S. Alward. "The Economic Impacts of a Foot-and-Mouth Disease Outbreak: A Regional Analysis." Journal of Agricultural and Applied Economics 39(October 2007):19-33.

Rich, K.M., and A. Winter-Nelson. "An Integrated Epidemiological-Economic Analysis of Foot and Mouth Disease: Applications to the Southern Cone of South America.” American Journal of Agricultural Economics 89,3(August 2007):682-97.

Rich, K.M., A. Winter-Nelson, and N. Brozović. "Modeling Regional Externalities with Heterogeneous Incentives and Fixed Boundaries: Applications to Foot and Mouth Disease Control in South America." Review of Agricultural Economics 27,3(2005):45664.

Schoenbaum, M.A., and W.T. Disney. "Modeling Alternative Mitigation Strategies for a Hypothetical Outbreak of Foot-and-Mouth Disease in the United States." Preventive Veterinary Medicine 58(2003):25-52.

Scudamore, J.M., and D.M. Harris. "Control of Foot and Mouth Disease: Lessons from the Experience of the Outbreak in Great Britain in 2001." Revue Scientifique et Technique 21(2002):699-710.

Shiflett, J.S., W.D. Purcell, D. Marsh, and P. Rodgers. Analysis of Lamb Demand in the United States. Denver, CO: Juniper Economic Consulting Inc., Report to the American Lamb Board, 2007.

Sutmoller, P., S.S. Barteling, R.C. Olascoaga, and K.J. Sumption. "Control and Eradication of Foot-and-Mouth Disease.” Virus Research 91(2003):101-44.

Tonsor, G.T., J.R. Mintert, and T.C. Schroeder. "U.S. Meat Demand: Household Dynamics and Media Information Impacts." Journal of Agricultural and Resource Economics 35(April 2010):1-17.

U.S. Department of Agriculture. 2007 Census of Agriculture. Washington, DC: U.S. Department of Agriculture, National Agricultural Statistics Service, December 2009.

U.S. Department of Homeland Security. National Bio and Agro-Defense Facility (NBAF): Updated Site-Specific Biosafety and Biosecurity Mitigation Risk Assessment. Washington, DC: U.S. Department of Homeland Security, Science and Technology Directorate, Final Report, February 2012.

Ward, M.P., L.D. Highfield, P. Vongseng, and M.G. Garner. "Simulation of Foot-and-Mouth Disease Spread with an Integrated Livestock System in Texas, USA." Preventative Veterinary Medicine 88,4(April 2009):286-97.

World Organisation for Animal Health (OIE). "Countries Notifying Foot and Mouth Disease in 2008 and 2009.” Internet site: http://www.oie.int/animal-healthin-the-world/fmd-portal/about-fmd/disease-information/ (Accessed September 18, 2012a).

—. “Terrestrial Animal Health Code." Internet site: http://www.oie.int/en/ international-standard-setting/terrestrial-code/ (Accessed September 18, 2012b).

Zhao, Z., T.I. Wahl, and T.L. Marsh. "Invasive Species Management: Foot-and-Mouth Disease in the U.S. Beef Industry." Agricultural and Resource Economics Review 35,1(April 2006):98-115.

Zheng, Y., and H.M. Kaiser. "Estimating Asymmetric Advertising Response: An Application to U.S. Nonalcoholic Beverage Demand.” Journal of Agricultural and Applied Economics 40,3(December 2008):837-49. 
Appendix A. Foot-and-Mouth Disease Duration, Animals Depopulated, and Animals Vaccinated by Scenario, 10th, 50th (Median), and 90th Disease Duration Percentiles

\begin{tabular}{|c|c|c|c|c|c|c|c|c|c|c|c|c|c|c|}
\hline \multirow[b]{2}{*}{ Scenario } & \multirow{2}{*}{$\begin{array}{c}\text { Disease } \\
\text { Duration } \\
\text { Percentile }\end{array}$} & \multirow{2}{*}{$\begin{array}{c}\text { Disease } \\
\text { Duration } \\
\text { Quarters }\end{array}$} & \multicolumn{6}{|c|}{ Animals Depopulated } & \multicolumn{6}{|c|}{ Animals Vaccinated } \\
\hline & & & Cow-Calf & Feedlot & Dairy & Swine & Sheep & Total & Cow-calf & Feedlot & Dairy & Swine & Sheep & Total \\
\hline \multirow{3}{*}{ NOVAC } & 10th & 1 & 9 & 48,732 & 7,514 & 9 & - & 56,263 & - & - & - & - & - & - \\
\hline & 50 th & 9 & 390,163 & $9,759,046$ & $1,058,290$ & $6,178,064$ & 61,946 & $17,447,509$ & - & - & - & - & - & - \\
\hline & 90th & 9 & 435,780 & $9,809,265$ & $1,053,300$ & $6,695,697$ & 93,848 & $18,087,890$ & - & - & - & - & - & - \\
\hline \multirow{3}{*}{ D5/10/10 } & 10th & 1 & 50 & 23,810 & - & 50 & 9 & 23,918 & - & - & - & - & - & - \\
\hline & 50th & 7 & 43,981 & $8,683,351$ & 296,612 & $1,039,183$ & 2,738 & $10,065,865$ & - & $7,823,610$ & - & - & - & $7,823,610$ \\
\hline & 90th & 9 & 46,964 & $9,070,348$ & 306,553 & $1,003,319$ & 6,018 & $10,433,201$ & 2,020 & $8,620,690$ & 4,766 & 77,305 & - & $8,704,781$ \\
\hline \multirow{3}{*}{ L5/10/10 } & 10th & 1 & 50 & 23,810 & - & 50 & 9 & 23,918 & - & - & - & - & - & - \\
\hline & 50 th & 7 & 43,981 & $8,683,351$ & 296,612 & $1,039,183$ & 2,738 & $10,065,865$ & - & $7,823,610$ & - & - & - & $7,823,610$ \\
\hline & 90th & 9 & 44,944 & $9,070,348$ & 301,787 & 926,014 & 6,018 & $10,349,110$ & 2,020 & $8,620,690$ & 4,766 & 77,305 & - & $8,704,781$ \\
\hline \multirow{3}{*}{$\mathrm{D} / 1 / 10 / 10$} & 10th & 4 & 60,319 & $7,936,405$ & 278,673 & $1,043,055$ & 7,215 & $9,325,667$ & - & $3,832,640$ & - & - & - & $3,832,640$ \\
\hline & 50th & 7 & 34,894 & $8,798,032$ & 205,660 & 922,733 & 4,696 & $9,966,015$ & - & $4,176,190$ & - & - & - & $4,176,190$ \\
\hline & 90th & 8 & 33,122 & $8,820,919$ & 240,603 & 517,354 & 5,834 & $9,617,832$ & - & $4,875,260$ & - & - & - & $4,875,260$ \\
\hline \multirow{3}{*}{ D5/10/50 } & 10th & 1 & 58 & 70,847 & - & - & 5 & 70,910 & - & 95,796 & - & - & - & 95,796 \\
\hline & 50th & 3 & 15,418 & $2,235,256$ & 47,423 & 225,481 & 553 & $2,524,130$ & - & $18,013,161$ & - & - & - & $18,013,161$ \\
\hline & 90th & 4 & 13,451 & $1,930,061$ & 38,976 & 138,688 & 606 & $2,121,782$ & - & $25,128,623$ & - & - & - & $25,128,623$ \\
\hline \multirow{4}{*}{ L5/10/50 } & 10th & 1 & 58 & 70,847 & - & - & 5 & 70,910 & - & 95,796 & - & - & - & 95,796 \\
\hline & 50th & 3 & 15,418 & $2,235,256$ & 47,423 & 225,481 & 553 & $2,524,130$ & - & $18,013,161$ & - & - & - & $18,013,161$ \\
\hline & 90th & 4 & 13,451 & $1,930,061$ & 38,976 & 138,688 & 606 & $2,121,782$ & - & $25,128,623$ & - & - & - & $25,128,623$ \\
\hline & 10th & 3 & 46,618 & $7,241,708$ & 302,229 & $1,381,101$ & 9,022 & $8,980,678$ & - & $8,011,320$ & - & - & - & $8,011,320$ \\
\hline \multirow[t]{2}{*}{ D1/10/50 } & 50th & 5 & 30,437 & $6,606,412$ & 245,518 & $1,135,144$ & 2,153 & $8,019,664$ & - & $11,040,700$ & - & - & - & $11,040,700$ \\
\hline & 90th & 7 & 130,231 & $8,856,961$ & $1,061,220$ & $6,540,623$ & 763 & $16,589,797$ & - & $9,572,040$ & - & - & - & $9,572,040$ \\
\hline \multirow{4}{*}{ D5/100/10 } & 10th & 2 & 230 & 142,760 & 770 & 119,402 & - & 263,161 & - & - & - & - & - & - \\
\hline & 50 th & 7 & 51,572 & $8,639,766$ & 257,767 & 964,073 & 18,699 & $9,931,877$ & 95 & $7,242,540$ & - & 24,589 & - & $7,267,223$ \\
\hline & 90th & 9 & 40,500 & $9,126,076$ & 287,080 & $1,047,014$ & 3,563 & $10,504,233$ & - & $8,000,780$ & - & - & - & $8,000,780$ \\
\hline & 10th & 2 & 230 & 142,760 & 770 & 119,402 & - & 263,161 & - & - & - & - & - & - \\
\hline L5/100/10 & 50 th & 7 & 51,478 & $8,639,766$ & 257,767 & 939,485 & 18,699 & $9,907,194$ & 95 & $7,242,540$ & - & 24,589 & - & $7,267,223$ \\
\hline
\end{tabular}


Appendix A. Continued.

\begin{tabular}{|c|c|c|c|c|c|c|c|c|c|c|c|c|c|c|}
\hline \multirow[b]{2}{*}{ Scenario } & \multirow{2}{*}{$\begin{array}{c}\text { Disease } \\
\text { Duration } \\
\text { Percentile }\end{array}$} & \multirow{2}{*}{$\begin{array}{c}\text { Disease } \\
\text { Duration } \\
\text { Quarters }\end{array}$} & \multicolumn{6}{|c|}{ Animals Depopulated } & \multicolumn{6}{|c|}{ Animals Vaccinated } \\
\hline & & & Cow-Calf & Feedlot & Dairy & Swine & Sheep & Total & Cow-calf & Feedlot & Dairy & Swine & Sheep & Total \\
\hline \multirow{5}{*}{ D5/100/50 } & 90th & 9 & 40,500 & $9,126,076$ & 287,080 & $1,047,014$ & 3,563 & $10,504,233$ & - & $8,000,780$ & - & - & - & $8,000,780$ \\
\hline & 10th & 2 & 1,597 & 147,229 & - & 13 & - & 148,839 & - & - & - & - & - & - \\
\hline & 50 th & 3 & 14,123 & $2,579,458$ & 48,502 & 396,810 & 1,407 & $3,040,300$ & - & $15,324,000$ & - & - & - & $15,324,000$ \\
\hline & 90th & 4 & 6,853 & $2,493,727$ & 53,625 & 153,295 & 1,640 & $2,709,139$ & - & $20,744,000$ & - & - & - & $20,744,000$ \\
\hline & 10th & 2 & 1,597 & 147,229 & - & 13 & - & 148,839 & - & - & - & - & - & - \\
\hline $\mathrm{L} 5 / 100 / 50$ & 90th & 4 & 6,853 & $2,493,727$ & 53,625 & 153,295 & 1,640 & $2,709,139$ & - & $20,744,000$ & - & - & - & $20,744,000$ \\
\hline \multirow{4}{*}{ D50/10/10 } & 10th & 1 & 10,539 & 100,878 & 3,476 & 617 & 992 & 116,501 & 9,683 & 11,032 & 237 & 548 & 992 & 22,491 \\
\hline & 50 th & 6 & 291,239 & $9,077,594$ & $1,118,339$ & $5,212,217$ & 36,976 & $15,736,364$ & 98,972 & $16,749,790$ & 70,129 & $1,073,420$ & 9,254 & $18,001,565$ \\
\hline & 90th & 9 & $3,063,206$ & $8,746,182$ & $1,079,033$ & $10,914,977$ & 15,310 & $23,818,708$ & $3,024,115$ & $12,119,800$ & 817,264 & $10,361,690$ & 9,614 & $26,332,483$ \\
\hline & 10th & 1 & 856 & 100,878 & 3,239 & 69 & - & 105,042 & 9,683 & 11,032 & 237 & 548 & 992 & 22,491 \\
\hline \multirow[t]{3}{*}{ L50/10/10 } & 50 th & 6 & 192,267 & $9,077,594$ & $1,048,210$ & $4,138,797$ & 27,722 & $14,484,589$ & 98,972 & $16,749,790$ & 70,129 & $1,073,420$ & 9,254 & $18,001,565$ \\
\hline & 90th & 9 & 39,091 & $8,746,182$ & 261,769 & 553,287 & 5,696 & $9,606,025$ & $3,024,115$ & $12,119,800$ & 817,264 & $10,361,690$ & 9,614 & $26,332,483$ \\
\hline & 10th & 2 & 1,650 & 474,598 & 25,405 & 24,866 & 18 & 526,537 & - & $8,599,870$ & - & - & - & $8,599,870$ \\
\hline \multirow{2}{*}{ D50/10/50 } & 90th & 5 & 7,874 & $1,805,344$ & 57,729 & 42,338 & 606 & $1,913,890$ & - & $32,210,570$ & - & - & - & $32,210,570$ \\
\hline & 10th & 2 & 1,650 & 474,598 & 25,405 & 24,866 & 18 & 526,537 & - & $8,599,870$ & - & - & - & $8,599,870$ \\
\hline L50/10/50 & 50th & 2 & 3,934 & 893,635 & 22,750 & 58,151 & 204 & 978,674 & - & $14,686,250$ & - & - & - & $14,686,250$ \\
\hline
\end{tabular}

